\title{
The Fabrication of Dielectric Elastomers From Silicone Rubber and Barium Titanate: Employing Equi-Biaxial Pre-Stretch to Achieve Large Deformations
}

\author{
Liang Jiang \\ Technological University Dublin \\ Tony Betts \\ Technological University Dublin, anthony.betts@tudublin.ie \\ David Kennedy \\ Technological University Dublin, david.kennedy@tudublin.ie
}

See next page for additional authors

Follow this and additional works at: https://arrow.tudublin.ie/scschcpsart

\section{Recommended Citation}

Jiang, L. et al. (2015) The fabrication of dielectric elastomers from silicone rubber and barium titanate: employing equi-biaxial pre-stretch to achieve large deformations. Journal of materials science50(24) pp. 1-9. DOI: $10.1007 / \mathrm{s} 10853-015-9357-6$

This Article is brought to you for free and open access by the School of Chemical and Pharmaceutical Sciences at ARROW@TU Dublin. It has been accepted for inclusion in Articles by an authorized administrator of ARROW@TU Dublin. For more information, please contact arrow.admin@tudublin.ie, aisling.coyne@tudublin.ie, gerard.connolly@tudublin.ie.

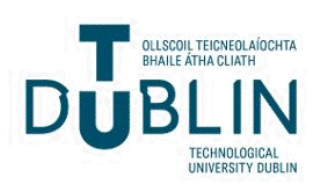




\section{Authors}

Liang Jiang, Tony Betts, David Kennedy, and Stephen Jerrams

This article is available at ARROW@TU Dublin: https://arrow.tudublin.ie/scschcpsart/48 


\title{
The fabrication of dielectric elastomers from silicone rubber and barium titanate: employing equi-biaxial pre-stretch to achieve large deformations
}

\author{
Liang Jiang ${ }^{1 \text { a }}$, Anthony Betts ${ }^{b}$, David Kennedy ${ }^{c}$, Stephen Jerrams ${ }^{\text {a }}$ \\ ${ }^{a}$ Centre for Elastomer Research (CER), Focas Research Institute, Dublin Institute of Technology, Dublin 8, \\ Ireland \\ ${ }^{\mathrm{b}}$ Applied Electrochemistry Group (AEG), Focas Research Institute, Dublin Institute of Technology, Dublin 8, \\ Ireland \\ ${ }^{\mathrm{c}}$ Department of Mechanical Engineering, Dublin Institute of Technology, Dublin 1, Ireland
}

\begin{abstract}
Barium titanate $\left(\mathrm{BaTiO}_{3}, \mathrm{BT}\right)$, which has a high dielectric constant was used as the filler in silicone rubber (SR) based DE composites. The BT was added in order to achieve higher voltage-induced strains and decrease the magnitude of the applied electric fields. The morphology of SR/BT composites was observed using a scanning electron microscope (SEM). The mechanical property of the SR/BT composites, which was characterized by an equi-biaxial static test, was obtained using a bubble inflation test system. Significantly, an optimum equi-biaxial pre-stretch ratio was determined using this method in order to enhance the actuated strain achieved under an applied electric field. Concurrently, the measurements of dielectric constant and loss tangent were carried out using dielectric spectroscopy. Using the pre-stretch ratio obtained from equi-biaxial testing, the influence of BT content on the electromechanical properties of SR based DEs was investigated. The results showed that the BT exhibited excellent dispersibility in SR matrices, but agglomerates appeared in the composites with higher filler content. An increase of dielectric constant was obtained by increasing the BT content in SR with low dielectric loss tangents below 0.035 at $0.1 \mathrm{~Hz}$ for all films. Also, the composite of SR/BT exhibited hyperelasticity with the minimum secant modulus at the optimised stretch ratio of 1.6. Under this specified pre-stretch ratio, a maximum actuated area strain of approximately $57 \%$ was achieved for the film having a filler loading of $20 \mathrm{wt} \% \mathrm{BT}$. This strain corresponded to a relatively low dielectric strength of around $46 \mathrm{~V} / \mu \mathrm{m}$. For all the DE composites tested, a maximum electromechanical energy density $(e)$ of $0.042 \mathrm{MJ} / \mathrm{m}^{3}$ and an electromechanical coupling efficiency $\left(K^{2}\right)$ of 0.59 were obtained for DEs with $30 \mathrm{wt} \%$ and $20 \mathrm{wt} \%$ BT respectively.
\end{abstract}

Keywords: Dielectric elastomers, Equi-biaxial mechanical test, Area strain, Dielectric strength, Energy density.

\section{Introduction}

DEs are a group of smart materials that respond to electrical stimulus by changing their shapes. DEs possess some major advantages over other smart materials such as light weight, low cost, the absence of noise pollution, large actuated strains (> $30 \%$ ), high energy densities and fast response times [1]. The large strain capabilities suggest that they can be used for artificial muscle in bionic applications, valves and actuators [2-4]. To date, the most widely used DE material is polyacrylate because of its ability to deliver large voltage-induced strain (> 100\%) [5]. However, the intrinsic drawbacks of this material have inevitably impeded its applications. These drawbacks include:

i) low thermal stability; modulus varies greatly with temperature change

ii) sensitivity to environmental degradation [6] and

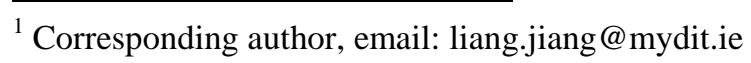


iii) viscoelasticity; the deformation is time-dependent (strain rate-dependent) which results in a relatively slow response to an electrical signal and limits coupling efficiency $[7,8]$.

SR cannot only overcome these shortcomings, but also has greater biocompatibility than most carbon based polymers [6]. Therefore, greater attention has been given to research into SR based DEs [9-11]. Generally, they work with compliant electrodes such as carbon grease or graphite spray coated onto their top and bottom surfaces [12,13]. When a high voltage is applied to the electrodes, an electrostatic pressure $\left(\sigma_{v}\right)$ compresses the DE which, due to the isochoric behaviour of the material, results in large equi-biaxial area strains occurring in the two planes mutually perpendicular to the direction of compression (refer to Fig. 1).

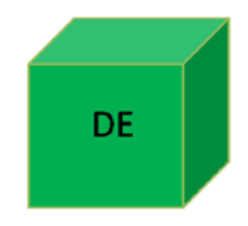

Reference state

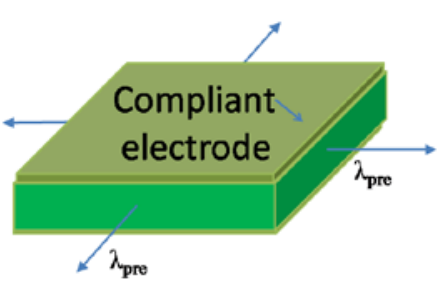

Pre-stretch state

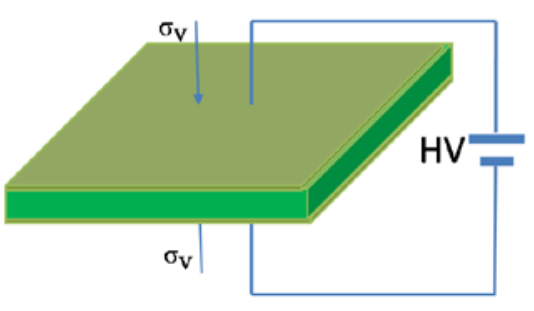

Deformed state

Fig. 1. The working principle of a DE.

A compressive force is created by applying a high voltage between the top and bottom surfaces of the DE in accordance with Eqn. (1) [5].

$\sigma_{\mathrm{V}}=\varepsilon^{\prime} \varepsilon_{0}(\phi / \mathrm{z})^{2}=\varepsilon^{\prime} \varepsilon_{0} \varphi^{2}$

where $\varepsilon^{\prime}$ is the relative permittivity of the DE material, $\varepsilon_{0}$ is the permittivity of the free space $\left(8.85 \times 10^{-12} \mathrm{~F} / \mathrm{m}\right), \varphi$ is the electric field which equals the applied high voltage $(\Phi)$ divided by the thickness of the DE $(z)$. Thickness strain $\left(s_{z}\right)$ under a high electric field can be approximated by the expression [14-16]

$S_{z}=\varepsilon^{\prime} \varepsilon_{0} \varphi^{2} / E$

where $\mathrm{E}$ is the elastic modulus of the $\mathrm{DE}$ material. As the material is assumed to be isochoric, the volume of a DE remains constant irrespective of whether a high voltage is applied. The strains in area have an interrelationship with thickness strain as expressed by Eqn. (3).

$s_{a}=1 /\left(1-\left|s_{z}\right|\right)-1$

It is evident from Eqn. (2) that a material of high dielectric constant combined with a low elastic modulus can achieve a large strain when subjected to a low electric field [14,17]. Therefore, particles such as titanium dioxide $\mathrm{TiO}_{2}$ [18,17], copper-phthalocyanine oligomer (CPO) [19] and BT [20] that all possess high dielectric constants are widely used as fillers, to enhance the dielectric constants of DE materials. This allowed actuated area strains of $15 \%$ - $35 \%$ to be achieved. Moreover, pre-stretching has been shown to be the key to developing large strains in these materials [21-23]. In an elastomer, the mobility of molecular chains can be restrained by intermolecular interactions [24]. However, intermolecular interactions can be diminished by stretching. This reduction is characterized by a drop in elastic modulus, hence the elastic modulus is highly dependent on stretch [25]. It has been reported that a low elastic modulus is of benefit in allowing DE materials to achieve large voltage-induced deformations [26]. Though pre-stretch can increase dielectric strength [27], the strain-stiffening effect prevents large deformation from occurring in an applied electric field. Based on these considerations, it is difficult to determine a pre-stretch which allows DEs to achieve large deformations. However, it is reasonable for a DE to obtain a larger deformation at a pre-stretch ratio where the composite exhibits a minimum elastic modulus for the introduction of a constant electric field.

It has been shown that a higher voltage-induced strain can be achieved by imposing an equi-biaxial pre-stretch on a film instead of applying a uniaxial pre-stretch [28,21]. However, most research into the mechanical properties of DEs was carried out using the conventional uniaxial tensile test [29,11]. In this work, initially a static mechanical equi-biaxial test was applied using a bubble inflation test 
system [30,31]. DEs with SR and BT were fabricated and subjected to equi-biaxial pre-stretch in order to obtain a large voltage-induced deformation under a relatively low electric field. The critical pre-stretch ratio was determined by investigating the mechanical equi-biaxial behaviour of material.

\section{Experimentation}

\subsection{Materials}

A commercial polymer, dimethylsiloxane (LSR4305 DEV, Bluestar Ltd., U.S.A), consisting of two parts (part A and part B) was used for fabricating the DE samples; NYOGEL 756G (Nye Lubricants, Inc., USA) was the conductive carbon grease used as the compliant electrode. The particle size of barium titanate was about $1 \mu \mathrm{m}$ and the density was $6.08 \mathrm{~g} / \mathrm{ml}$ at $25{ }^{\circ} \mathrm{C}$. The BT was supplied by Sigma-Aldrich Co. LLC and was added to the silicone to improve the dielectric constant of the composites.

\subsection{Sample preparation}

The two part polymer was initially mixed at a ratio of $1: 1$. Then, BT was subsequently added to the silicone matrix with filler contents of $0 \mathrm{wt} \%, 10 \mathrm{wt} \%, 20 \mathrm{wt} \%, 30 \mathrm{wt} \%$, $40 \mathrm{wt} \%$ and $50 \mathrm{wt} \%$, respectively. The DE composites were mechanically stirred to provide a high level of dispersibility of particles in SR. The entire mixture was degassed in a vacuum to remove entrapped air bubbles prior to being poured into a mould. After degassing for at least 1.5 hours, the compound was solidified in an oven at a temperature of $80^{\circ} \mathrm{C}$ for about 12 hours. Finally, DE samples of $0.3 \mathrm{~mm}$ and $2 \mathrm{~mm}$ thickness were obtained using two alternative moulds.

\subsection{Microscopy observation}

The microstructures of all DE samples with a thickness of $2 \mathrm{~mm}$ were examined using a Scanning Electron Microscope (SEM, Zeiss Supra). The samples were cut at room temperature to create new surfaces which were then coated with a fine layer of gold to make them conductive prior to observation. All images were taken with an accelerating voltage of $5 \mathrm{KV}$ using an SE (Secondary Electron) detector.

\subsection{Mechanical tests}

The bubble inflation test system [32] (Refer to Fig. 2) was designed for the equi-biaxial mechanical testing of elastomers by means of hydraulically inflating and deflating test samples using silicone oil. Disc samples of $50 \mathrm{~mm}$ nominal diameter were prepared and for mechanical testing were constrained in the bubble inflation system's inflation orifice. In the static tests, pressure was applied to the samples of $2 \mathrm{~mm}$ thickness causing them to inflate. The vision system, utilising two charge coupled device (CCD) cameras, recorded the movement of the centres of specific points at the pole on the surface of the samples during inflation. Stress values were simultaneously calculated from the applied pressure and bubble geometry, while strain (or stretch ratio) values were calculated from the change in circumferential distance between the centres of the specific points on the bubble surface at the bubble pole using three dimensional position coordinates obtained from the vision system output. This allowed the relation between stress and strain (or stretch ratio) to be obtained simultaneously. 


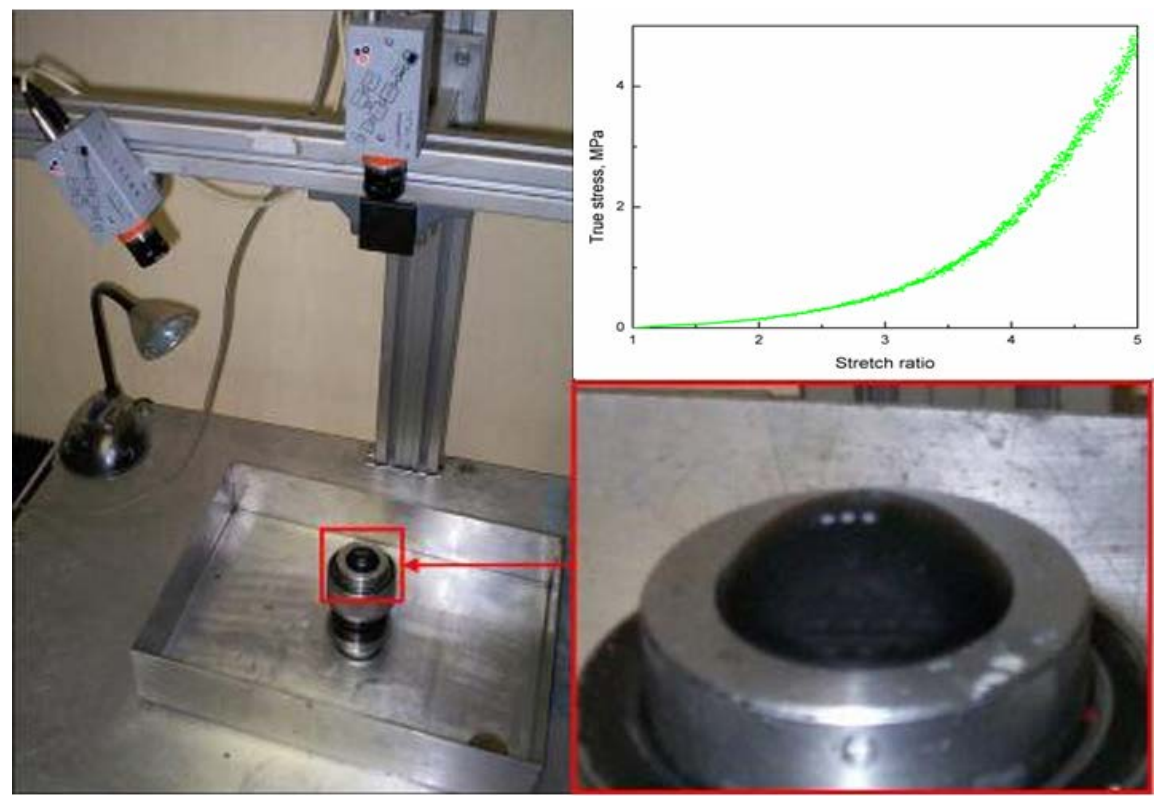

Fig. 2. Photographs showing a sample undergoing testing in the bubble inflation test system, together with a calibration curve of stretch ratio vs true stress.

\subsection{Broadband dielectric spectroscopy}

Dielectric measurements of SR/BT films were conducted on a Turnkey broadband dielectric spectrometer at $20^{\circ} \mathrm{C}$ in the frequency range from $0.1 \mathrm{~Hz}$ to $10 \mathrm{MHz}$. The film of approximate 0.3 $\mathrm{mm}$ was placed on a cell which was a disposable gold-plated flat electrode with a diameter of $20 \mathrm{~mm}$ and thickness of $2 \mathrm{~mm}$.

\subsection{Electromechanical tests}

The electromechanical test system consists of a camera, a biaxial clamp to apply pre-stretching and a high voltage power supply. Samples of $0.3 \mathrm{~mm}$ thickness were coated with the compliant electrode material. The samples were clamped with a pre-stretch ratio applied to them and a camera recorded changes in their area when an electric field was incrementally applied in voltage steps of $0.5 \mathrm{kV}$ at 10 seconds interval. Thereafter, the area was accurately measured using AutoCAD software.

\section{Results and Discussion}

\subsection{Microstructure of DEs}

The morphology and particle distribution in the SR composites were studied using SEM. Figs. 3 (a) (f) display the micrographs for variations in BT content from $0 \mathrm{wt} \%$ to $50 \mathrm{wt} \%$ respectively. It is evident that the particles were uniformly dispersed in the SR matrices. In addition, agglomerations of BT particles of different size dependent on particle content were observed. These micrographs reveal that at higher filler loadings, the BT particle tended to produce larger agglomerates and therefore large voids were capable of occurring at interfaces between the filler particles and the SR matrix. 


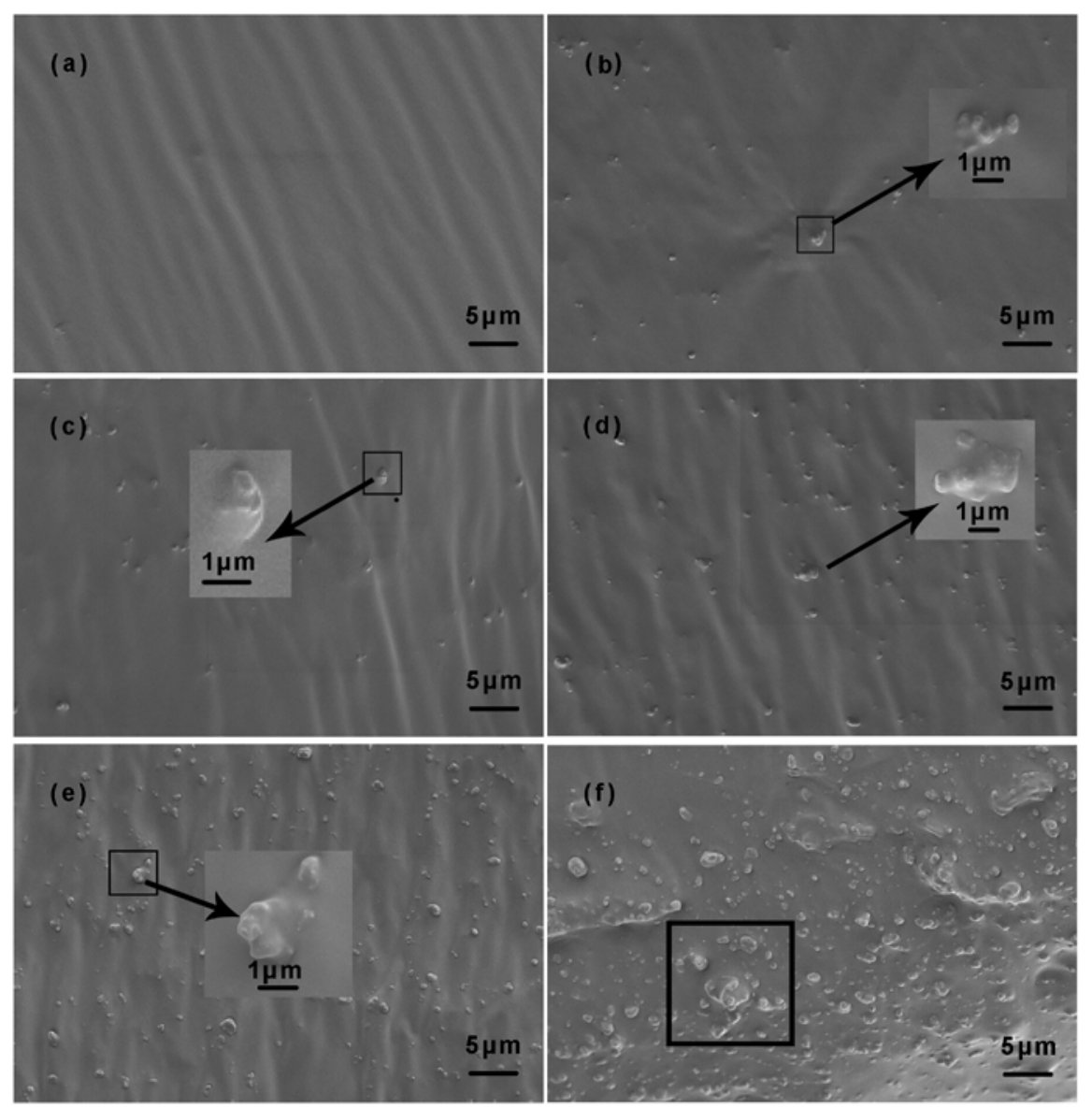

Fig. 3.Micrographs of SR composites with different filler loadings: (a) $0 \mathrm{wt} \%$; (b) $10 \mathrm{wt} \%$; (c) 20 wt\%; (d) 30 wt\%; (e) 40 wt\%; (f) 50 wt\%.

\subsection{Stress-stretch and secant modulus-stretch behaviour}

Fig. 4 shows the relation between equi-biaxial true stress and stretch ratio for the silicone rubber composites for varied BT contents by weight. As can be observed, the true stress was less than $8 \mathrm{MPa}$ for all samples when subjected to equi-biaxial stretch up to a stretch ratio of 5 . The stress increased approximately linearly with increases in stretch ratio for stretch areas from 1 to about 1.2. The slope of the initial linear part of the stress-stretch curve decreased as the filler concentration increased indicating that stiffness reduced as filler loading increased. All samples used in this test exhibited hyperelastic deformation. 


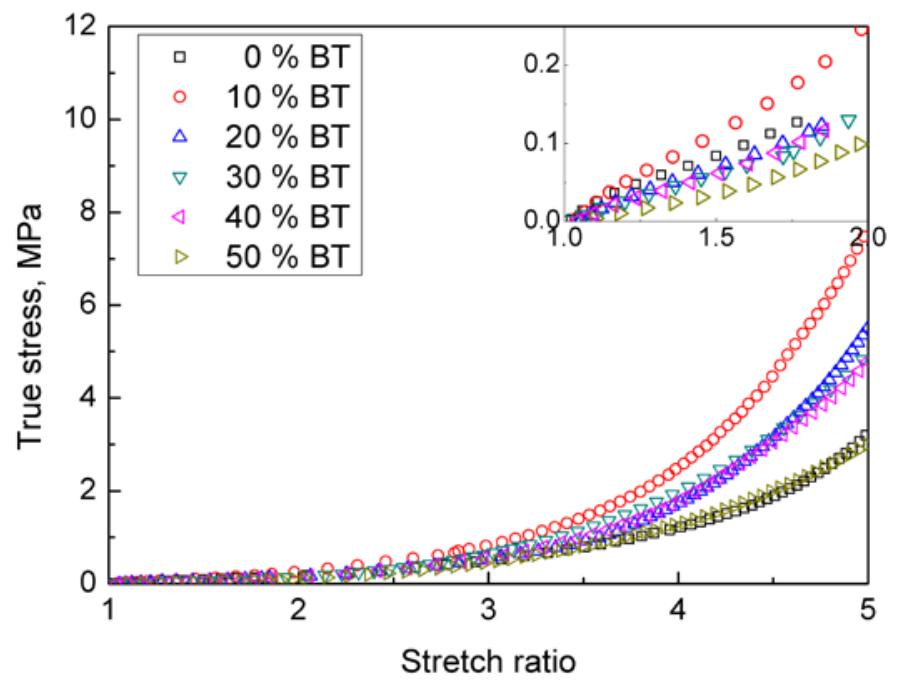

Fig. 4. True stress related to stretch ratio curves for silicone rubber with various barium titanate contents.

The curves of secant modulus related to stretch ratio for these composites are plotted in Fig. 5. As can be observed from Fig. 4, the linear elastic portion of all the stress-stretch curves was below the stretch ratio of 1.2 where the slope of all curves indicates the initial Young's modulus [33]. Therefore, the stiffness of these composites (apart from the sample with $10 \mathrm{wt} \% \mathrm{BT}$ ) was lower than that of the pure silicone. The increased stiffness of DE sample with $10 \mathrm{wt} \%$ BT is probably due to enhanced intermolecular forces occurring for this specific particle content. Furthermore, as shown in Fig. 5, these curves, which are affected by the intermolecular forces between particles and matrices, exhibit a single critical point indicating that the stiffness of these materials can be reduced by stretching them to small ratios. It can be observed that the minimum elastic moduli were obtained at a stretch ratio of approximately 1.6. In line with Eqn. (2), it is reasonable to assume that a maximum voltage-induced area strain from pre-stretching can be obtained at this stretch ratio.

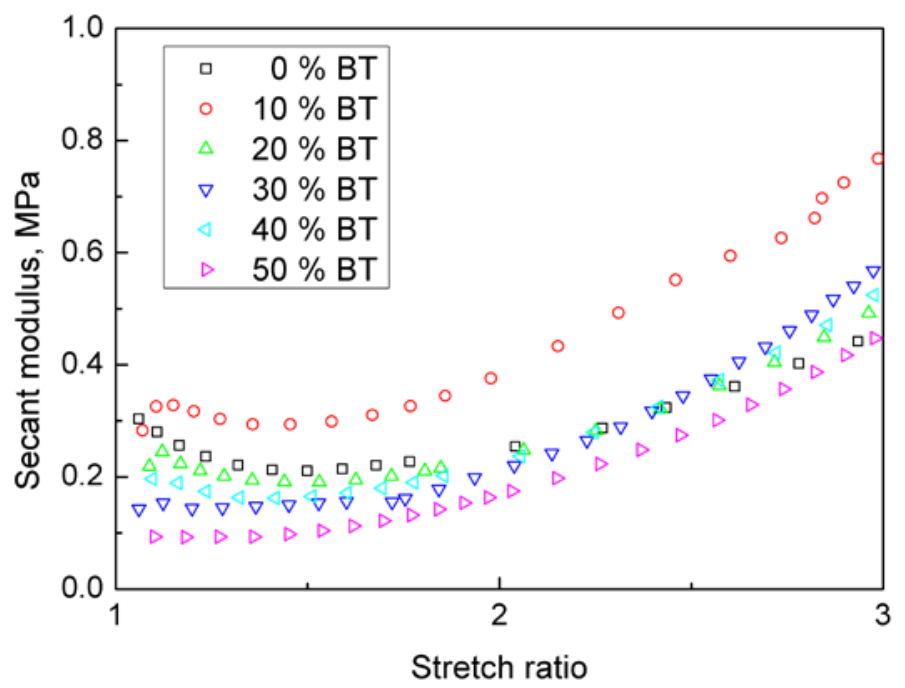

Fig. 5. Secant modulus of silicone composites with varied BT content related to stretch ratio.

\subsection{Dielectric properties of DE composites}

The applied electric field necessary to cause a required deformation can be decreased by increasing the dielectric constant in a DE composite on the basis of Eqn. (2). The complex dielectric constant which is also known as the relative permittivity, $\varepsilon=\varepsilon^{\prime}-j \varepsilon^{\prime \prime}$, comprises the real part $\left(\varepsilon^{\prime}\right)$ and the imaginary part $\left(\varepsilon^{\prime \prime}\right)$ which contributes to the energy loss. The dielectric spectra of the unfilled silicone matrix and the composites are shown in Fig. 6 and Fig. 7 respectively for $\varepsilon^{\prime}$ and the dielectric loss 
tangent (tan $\delta=\varepsilon^{\prime \prime} / \varepsilon$ ). As observed in Fig.6, the relative permittivity $\varepsilon^{\prime}$ increased gradually with increasing content of filler for the silicone possessing a permittivity of about 2.9 at $1 \mathrm{kHz}$, due to the strong presence of Maxwell-Wagner interfacial polarization [34]. The silicone rubber with BT loading of $50 \mathrm{wt} \%$ displayed the highest permittivity of approximately 6.3 at $1 \mathrm{kHz}$. All curves fluctuated slightly in the wide band frequency from $0.1 \mathrm{~Hz}$ to $1 \mathrm{MHz}$. Because the particles bonded strongly with the matrices at low filler loadings, the molecular networks in the polymers restricted the mobility of molecular chains. Additionally, polymer chain entanglements were regarded as a factor in restricting the movement of polymer chains. Thus, the dielectric constant was hardly affected by changes in frequency [35]. Furthermore, there is evidence that the amorphous SR is not influenced by dipole orientation due to the molecular structure at room temperature [36].

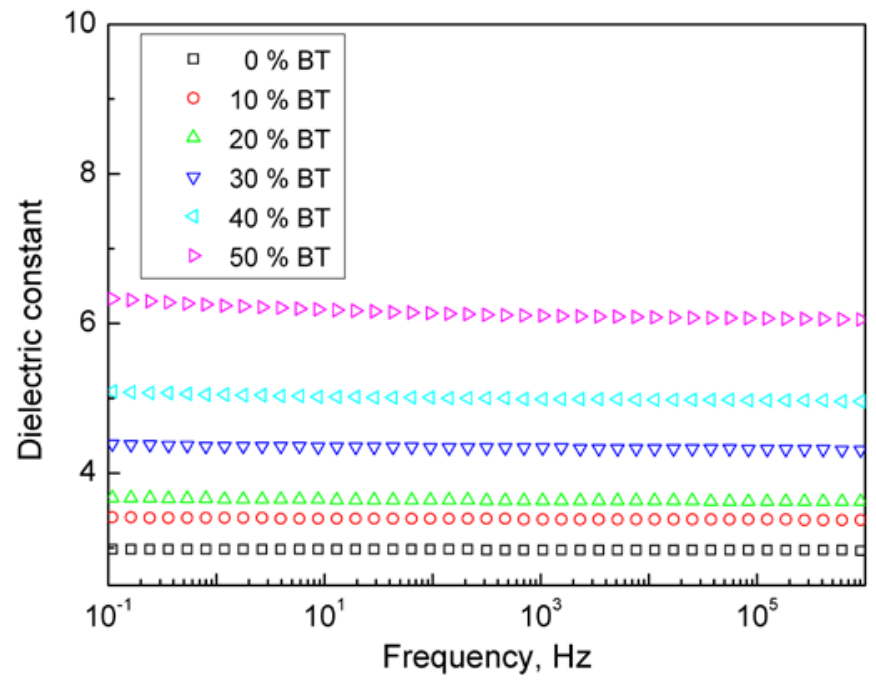

Fig. 6. Effect of BT content on the dielectric constant of SR as a function of frequency.

The dielectric loss tangent is a physical parameter of a DE useful for characterizing its inherent dissipation of electromagnetic energy. When the value of loss tangent increases, it indicates that greater polarization occurs as energy losses increase. Fig.7 shows that $\tan \delta$ decreased markedly for all samples up to a frequency of approximately $10 \mathrm{~Hz}$. The unfilled silicone had a minimum $\tan \delta$ of about 0.012 at $0.1 \mathrm{~Hz}$. In addition, the dielectric loss tangent increased with increasing filler content at frequencies above $1 \mathrm{~Hz}$. This is because the presence of agglomerations and defects in the SR/BT composites increased the dielectric loss tangent [35]. However, there is no general trend for the change of dielectric loss tangent against BT contents at frequencies below $1 \mathrm{~Hz}$ because the conductivity of polymer composites also contributed to the dielectric loss in this low frequency range [37].

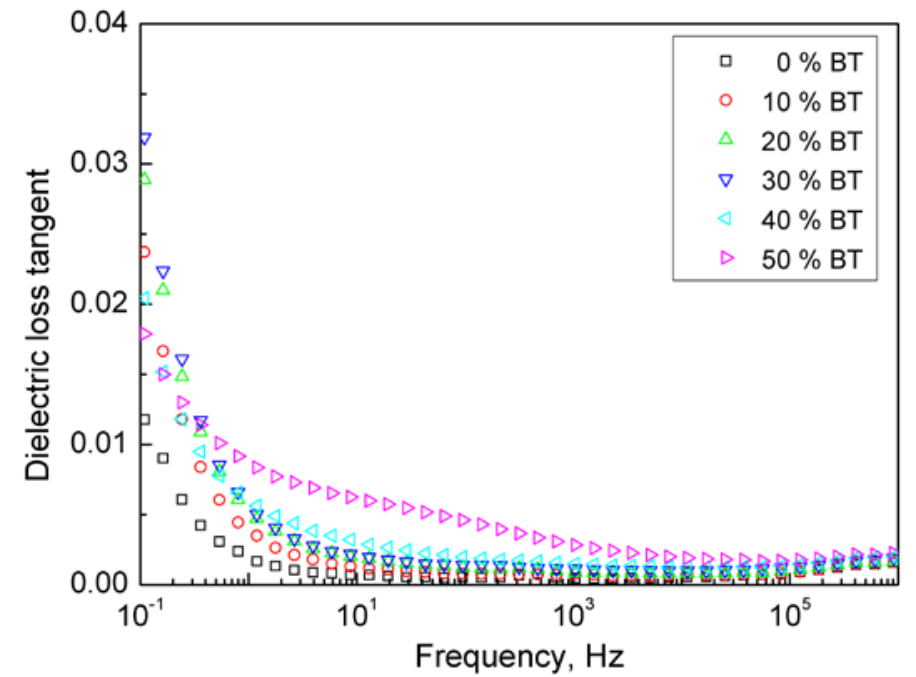

Fig. 7. Effect of BT content on the dielectric loss tangent of SR composites as a function of frequency. 
In order to improve understanding of the dielectric behaviour of DEs, several mixing rules [1,38-41] have been proposed for simulating the dielectric constant $\left(\varepsilon^{\prime}\right)$ of polymer composites which comprise the isotropic dielectric matrix (dielectric constant $\varepsilon_{1}{ }^{\prime}$, volume fraction $v_{1}$ ), filled with dielectric spheroids (dielectric constant $\varepsilon_{2}{ }^{\prime}$, volume fraction $v_{2}=1-v_{1}$ ). The following equations are used to express the relations between the dielectric constant of DEs and the volume fraction of spherical fillers in DEs:

The Maxwell-Wagner formula (Eqn. (4)) describes the change of dielectric properties of a diluted suspension with spherical conducting particles. It is derived under the assumption that particles are dispersed in a continuous matrix phase in such a low concentration that there is no interaction between particles.

$$
\varepsilon^{\prime}=\varepsilon_{1}^{\prime}\left[1+\frac{3 v_{2}\left(\varepsilon_{2}^{\prime}-\varepsilon_{1}^{\prime}\right)}{2 \varepsilon_{1}^{\prime}+\varepsilon_{2}^{\prime}-v_{2}\left(\varepsilon_{2}^{\prime}-\varepsilon_{1}^{\prime}\right)}\right]
$$

When the particle volume concentration is high, the assumption is invalid. In order to overcome this disadvantage, a formula was proposed by Böttcher:

$$
\frac{\varepsilon^{\prime}-\varepsilon_{1}^{\prime}}{3 \varepsilon^{\prime}}=\frac{v_{2}\left(\varepsilon_{2}^{\prime}-\varepsilon_{1}^{\prime}\right)}{2 \varepsilon^{\prime}+\varepsilon_{2}^{\prime}}
$$

In accordance with Maxwell's equation, Looyenga developed an equation by assuming that the variable particle volume concentration was a function of $\varepsilon^{\prime}$ and $\Delta \varepsilon$ provided that $\varepsilon_{1}{ }^{\prime}=\varepsilon^{\prime}-\Delta \varepsilon$ and $\varepsilon_{2}{ }^{\prime}=$ $\varepsilon^{\prime}+\Delta \varepsilon$. The equation is expressed as:

$$
\varepsilon^{\prime}=\left[\left(1-v_{2}\right) \varepsilon_{1}^{\prime(1 / 3)}+v_{2} \varepsilon_{2}^{\prime(1 / 3)}\right]^{3}
$$

The modified Rother-Lichtenecker model [38,42] based on the Rother-Lichtenecker equation is a representation of a logarithmic law of mixing for a chaotic or statistical mixture, as shown in Eqn. (7):

$$
\ln \varepsilon^{\prime}=\ln \varepsilon_{1}^{\prime}+v_{2}(1-\kappa)\left(\ln \varepsilon_{2}^{\prime}-\ln \varepsilon_{1}^{\prime}\right)
$$

where $\kappa$ is a shape-dependent parameter. It was reported that $\kappa$ had a value around $0.1-0.3$ for most well-dispersed polymer-ceramic composites [43]. For example, a $\kappa$ of 0.1 was reported for a compound DE material consisting of a form of lead-free perovskite ceramic particle $\left(\mathrm{CaTiO}_{3}\right)$ in a polyvenylidene fluoride [44]. Jayasundere and Smith derived Eqn. (8) for permittivity as a randomly connected state in a binary piezoelectric 0-3 composite by modifying the well-known Kerner equation [45] including interactions between neighbouring spheres.

$$
\varepsilon^{\prime}=\frac{\varepsilon_{1}^{\prime} v_{1}^{\prime}+\frac{3 \varepsilon_{1}^{\prime} \varepsilon_{2}^{\prime} v_{2}}{2 \varepsilon_{1}^{\prime}+\varepsilon_{2}^{\prime}}\left[1+\frac{3 v_{2}\left(\varepsilon_{2}^{\prime}-\varepsilon_{1}^{\prime}\right)}{2 \varepsilon_{1}^{\prime}+\varepsilon_{2}^{\prime}}\right]}{v_{1}+\frac{3 \varepsilon_{1}^{\prime} v_{2}}{2 \varepsilon_{1}^{\prime}+\varepsilon_{2}^{\prime}}\left[1+\frac{3 v_{2}\left(\varepsilon_{2}^{\prime}-\varepsilon_{1}^{\prime}\right)}{2 \varepsilon_{1}^{\prime}+\varepsilon_{2}^{\prime}}\right]}
$$


A relationship was observed between the volume faction and the weight percentage relying on the density of the matrix $\left(1.07 \mathrm{~g} / \mathrm{cm}^{3}\right)$ and the filler $\left(6.08 \mathrm{~g} / \mathrm{cm}^{3}\right)$ in these experiments.

$v_{2}=\frac{1.07 m}{6.08-5.01 m}$

The curve fitting for dielectric constant of SR/BT composites by means of these equations (4 - 8) in conjunction with the volume fraction expression (Eqn. (9)) is shown in Fig. 8. As can be seen from this figure, the result obtained by utilising the Rother-Lichtenecker equation with $\kappa=0.2$ was the best fit with the experimental data. However, the dielectric constant of all the DE films calculated from the other equations was significantly smaller than the experimental data. The best-fit $\kappa$-value $(0.2)$ determined from the modified Rother-Lichtenecker expression indicates that the ceramic BT particles are reasonably well-dispersed. This $\kappa$-value lies between that of low values associated with small (often nano-sized) particles [46] and larger ceramic particles [43]. In practice $\kappa$ often reflects the size and orientation of embedded ceramic particles.

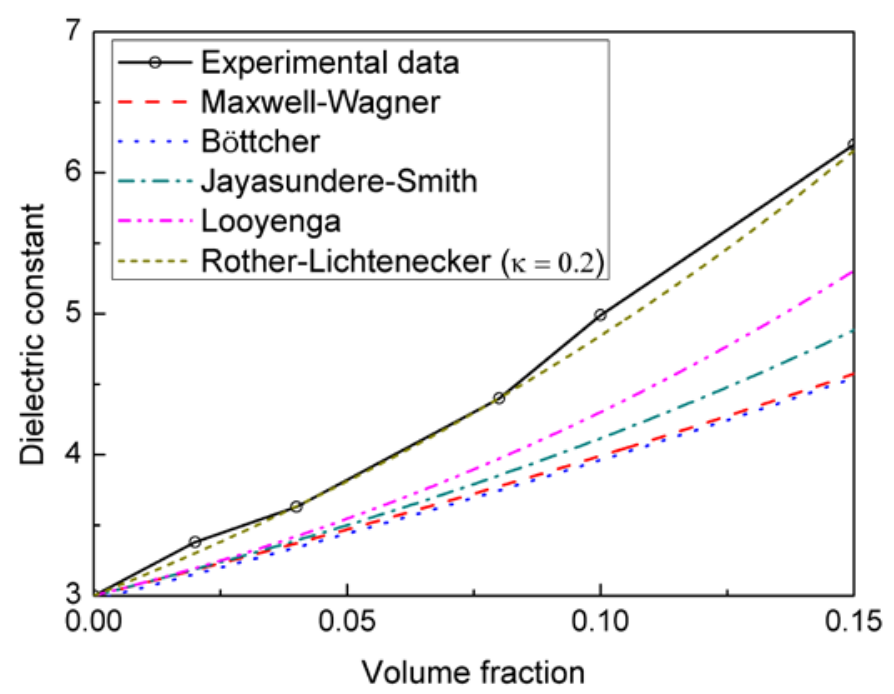

Fig. 8. Dielectric constant related to the BT content.

\subsection{Voltage-induced strain}

Samples of SR fabricated with different filler loadings ranging between $0 \%$ and $50 \%$ in $10 \%$ increments by weight were bonded to the equi-biaxial clamps at a pre-stretch ratio of 1.6 prior to high voltages being applied to them. Fig. 9 shows that area strains for all samples actuated by high voltages increased greatly with increases in electric field strength, mainly due to the voltage-induced strain dependent on electric field strength as expressed in Eqn. (2). All the samples containing BT exhibited higher actuated area strains than the pure SR sample. As can be seen from the curves, the actuated area strains increased with increasing content of BT. The SR composite with $20 \mathrm{wt} \% \mathrm{BT}$ achieved an area strain of $57 \%$ under an electric field of $46 \mathrm{~V} / \mu \mathrm{m}$ which is larger than that obtained by the unfilled silicone rubber that only produced an actuated area strain of $34 \%$ with a dielectric strength of $43 \mathrm{~V} / \mu \mathrm{m}$. Hence, the composite with $20 \mathrm{wt} \% \mathrm{BT}$ displayed the most pronounced electromechanical effect. 


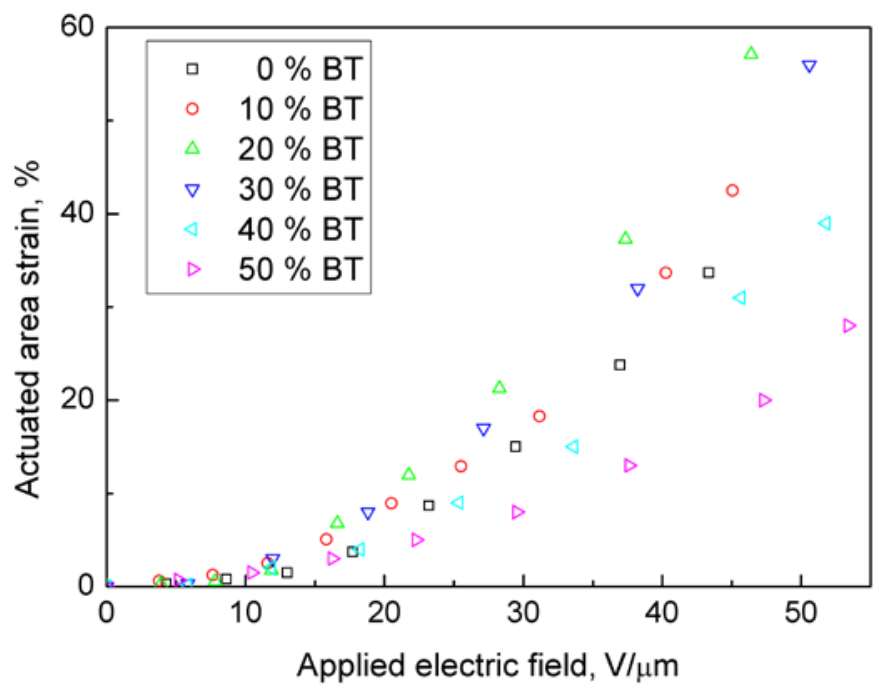

Fig. 9. The actuated area strain related with applied electric field.

The electromechanical sensitivity $(\beta)$, which is the ratio of dielectric constant to elastic modulus, was considered a significant value in determining voltage-induced deformation [16]. As can be seen from Fig. 10, sensitivity increased with an increase in BT content in SR composites. However, the voltage-induced area strain displayed a maximum value of $57 \%$ for a filler content of $20 \mathrm{wt} \%$, but was surprisingly lower at $28 \%$ for the SR composite with $50 \mathrm{wt} \%$ BT. This is possibly due to the viscoelasticity of the samples with higher filler content restricting large voltage-induced deformation. Also, defects in DE composites were regarded as a factor contributing to reductions in breakdown voltage [47], this also led to small voltage-induced deformations. In addition, energy loss increased with increasing dielectric loss tangent. This possibly relates directly to the heat increase associated with increase in filler content [48]. Consequently, the energy loss contributed to the decrease of breakdown voltage for the DE films.

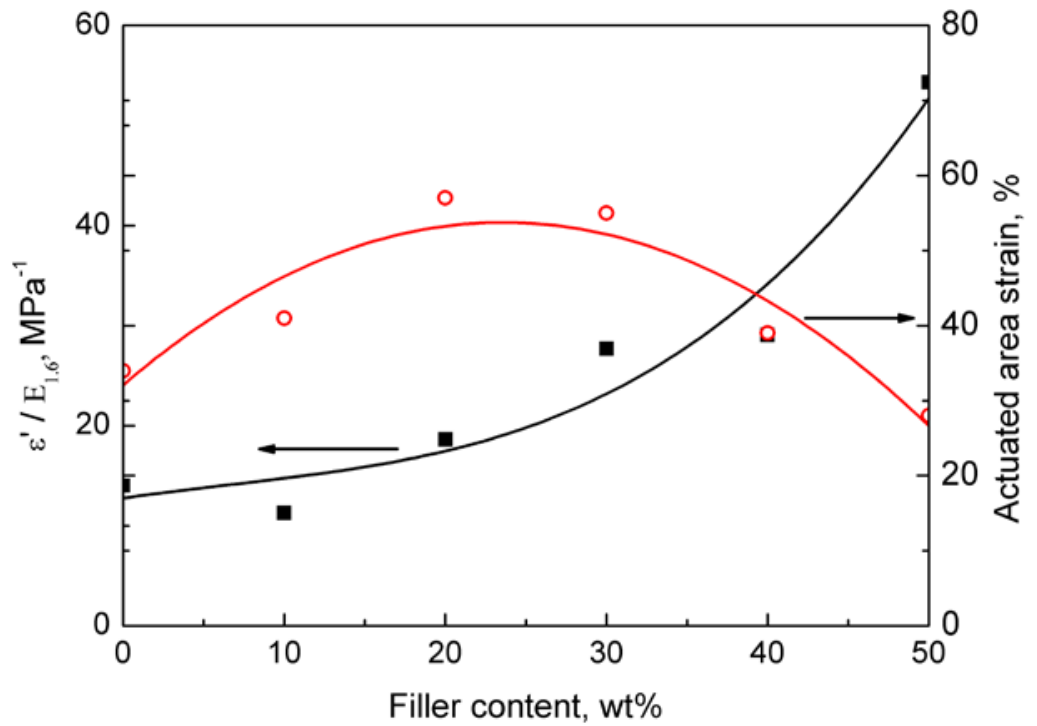

Fig. 10. The ratio of dielectric constant to secant modulus at $\lambda_{\text {pre }}=1.6$ and the voltage-induced strain related to the BT filler content in SR composites.

For a DE, electromechanical energy density $(e)$ is the amount of work generated in one actuation cycle per unit volume of actuator. The electromechanical coupling efficiency $\left(K^{2}\right)$ is the electrical energy converted into mechanical energy per cycle, so is a measure of the electrical energy that needs to be supplied to provide a level of mechanical energy (or physical actuation). Each parameter is of importance when characterizing the energy efficiency produced by a DE. ' $e$ ' and ' $K$ ' are obtained from Eqn. (10) and Eqn. (11) [6] respectively. 
$e=-\sigma_{V} \ln \left(1-\left|s_{z}\right|\right)$

$K^{2}=2\left|s_{z}\right|-s_{z}^{2}$

The dependence of electromechanical energy density and electromechanical coupling efficiency on filler content is shown in Fig. 11. As can be observed from this figure, both energy density and electromechanical coupling efficiency rises with increased filler content to about $20 \mathrm{wt} \%$, then decreased with an increase in filler content thereafter. Hence, the energy density for SR composites with $50 \mathrm{wt} \%$ BT was smaller than for DEs with $30 \mathrm{wt} \%$ BT which exhibited the largest electromechanical energy densities in the region of $0.042 \mathrm{MJ} / \mathrm{m}^{3}$, (3 times greater than that of pure silicone rubber) and the maximum electromechanical coupling efficiency $K^{2}$ of 0.59 .

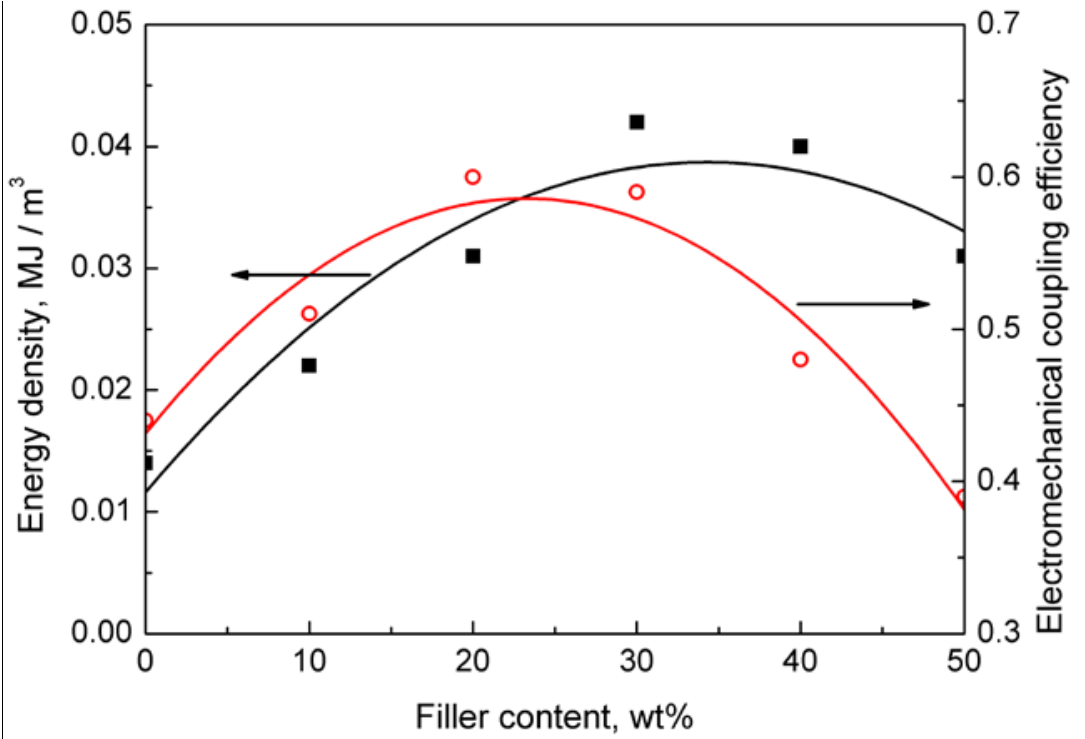

Fig. 11. The dependence of electromechanical energy density and electromechanical coupling efficiency on BT content.

\section{Conclusions}

SR is an excellent candidate for fabricating DEs with BT used as a filler. The SR based DE samples used in this research are soft and capable of high extensibility. The moduli of elasticity for the materials are low which allows them to achieve high area strains when employed in DE devices. In addition, an optimum equi-biaxial pre-stretch ratio of 1.6 was determined by means of equibiaxial mechanical testing. By comparison with conventional uniaxial testing, the equi-biaxial loading method is more representative and appropriate for defining the mechanical properties and is therefore a far more reliable indicator of properties displayed in practical applications of DEs. Furthermore, the dielectric constants for this range of DEs increased with increasing filler content, while dielectric loss tangent also increased at a frequency of $0.1 \mathrm{~Hz}$. This means that the more filler that was added, the more heat and energy loss generated. This effect, associated with increased agglomeration, and other defects in the composites having higher filler content inhibited the increases in dielectric strength. Finally, the maximum voltage-induced area strain of $57 \%$ together with an electromechanical coupling efficiency of 0.59 was achieved for an SR with $20 \mathrm{wt} \%$ BT by employing an electric field of $46 \mathrm{~V} / \mu \mathrm{m}$.

\section{Acknowledgements}

The authors gratefully acknowledge the support provided by the DIT Fiosraigh Dean of Graduate Students Award. 


\section{References}

1. Yang D, Tian M, Dong YC, Kang HL, Gong DL, Zhang LQ (2013) A high-performance dielectric elastomer consisting of bio-based polyester elastomer and titanium dioxide powder. J Appl Phys 114 (15):9. doi:10.1063/1.4824805

2. Madden JDW, Vandesteeg NA, Anquetil PA, Madden PGA, Takshi A, Pytel RZ, Lafontaine SR, Wieringa PA, Hunter IW (2004) Artificial muscle technology: physical principles and naval prospects. Oceanic Engineering, IEEE Journal of 29 (3):706-728. doi:10.1109/JOE.2004.833135

3. Yujuan $\mathrm{X}$, Zhimin $\mathrm{D}$, Junwei Z, Hongtao S, Changyong S, Bai J Carbon black-BaTiO $<$ inf $>3</$ inf $>$ /silicone rubber electroactive nanocomposites with large strain coefficient. In: Properties and Applications of Dielectric Materials, 2009. ICPADM 2009. IEEE 9th International Conference on the, 19-23 July 2009 2009. pp 793-795. doi:10.1109/ICPADM.2009.5252166

4. McKay TG, Gisby TA, Anderson IA Artificial muscles harvesting sensational power using self-sensing. In, 2014. pp 905603-905603-905607

5. Pelrine R, Kornbluh R, Pei Q, Joseph J (2000) High-Speed Electrically Actuated Elastomers with Strain Greater Than 100\%. Science 287 (5454):836-839. doi:10.1126/science.287.5454.836

6. Shankar R, Ghosh TK, Spontak RJ (2007) Dielectric elastomers as next-generation polymeric actuators. Soft Matter 3 (9):1116-1129

7. Sheng JJ, Chen HL, Liu L, Zhang JS, Wang YQ, Jia SH (2013) Dynamic electromechanical performance of viscoelastic dielectric elastomers. J Appl Phys 114 (13):8. doi:10.1063/1.4823861

8. Rosset S, O’Brien BM, Gisby T, Xu D, Shea HR, Anderson IA (2013) Self-sensing dielectric elastomer actuators in closed-loop operation. Smart Mater Struct 22 (10):104018

9. Galantini F, Carpi F, Gallone G (2013) Effects of plasticization of a soft silicone for dielectric elastomer actuation. Smart Mater Struct 22 (10):7. doi:10.1088/0964-1726/22/10/104020

10. Carpi F, Gallone G, Galantini F, De Rossi D Enhancement of the electromechanical transduction properties of a silicone elastomer by blending with a conjugated polymer. In, 2008. pp 692707-692707-692711

11. Michel S, Zhang XQ, Wissler M, Löwe C, Kovacs G (2010) A comparison between silicone and acrylic elastomers as dielectric materials in electroactive polymer actuators. Polymer International 59 (3):391-399. doi:10.1002/pi.2751

12. Pelrine R, Kornbluh R, Joseph J, Heydt R, Pei Q, Chiba S (2000) High-field deformation of elastomeric dielectrics for actuators. Materials Science and Engineering: C 11 (2):89-100. doi:http://dx.doi.org/10.1016/S0928-4931(00)00128-4

13. Yang D, Zhang L, Liu H, Dong Y, Yu Y, Tian M (2012) Lead magnesium niobate-filled silicone dielectric elastomer with large actuated strain. Journal of Applied Polymer Science 125 (3):2196-2201. doi:10.1002/app.36428

14. Tian M, Yao Y, Liu S, Yang D, Nishi T, Zhang L, Ning N (2014) Separated-structured all-organic dielectric elastomer with large actuation strain under ultralow-voltage and high mechanical strength. J Mater Chem A. doi:10.1039/C4TA04197F

15. Yang D, Tian M, Kang H, Dong Y, Liu H, Yu Y, Zhang L (2012) New polyester dielectric elastomer with large actuated strain at low electric field. Materials Letters 76 (0):229-232. doi:http://dx.doi.org/10.1016/j.matlet.2012.02.084

16. Yang D, Tian M, Li D, Wang W, Ge F, Zhang L (2013) Enhanced dielectric properties and actuated strain of elastomer composites with dopamine-induced surface functionalization. J Mater Chem A 1 (39):12276-12284. doi:10.1039/C3TA12090B

17. Ouyang G, Wang K, Chen XY (2012) TiO 2 nanoparticles modified polydimethylsiloxane with fast response time and increased dielectric constant. Journal of Micromechanics and Microengineering 22 (7):074002

18. Liu HL, Zhang LQ, Yang D, Yu YC, Yao L, Tian M (2013) Mechanical, Dielectric, and Actuated Strain of Silicone Elastomer Filled with Various Types of TiO2. Soft Mater 11 (3):363-370

19. Zhang X, Wissler M, Jaehne B, Breonnimann R, Kovacs G Effects of crosslinking, prestrain, and dielectric filler on the electromechanical response of a new silicone and comparison with acrylic elastomer. In, 2004. pp 78-86 
20. Zhang Z, Liu L, Fan J, Yu K, Liu Y, Shi L, Leng J New silicone dielectric elastomers with a high dielectric constant. In, 2008. pp 692610-692610-692618

21. Qiang J, Chen H, Li B (2012) Experimental study on the dielectric properties of polyacrylate dielectric elastomer. Smart Mater Struct 21 (2):025006

22. Koh SJA, Li T, Zhou J, Zhao X, Hong W, Zhu J, Suo Z (2011) Mechanisms of large actuation strain in dielectric elastomers. Journal of Polymer Science Part B: Polymer Physics 49 (7):504-515. doi:10.1002/polb.22223

23. Tianhu $\mathrm{H}$, Guanghong $\mathrm{M}$, Cheng $\mathrm{C}$ The effect of prestretch on the performance of a dielectric elastomer membrane. In: Remote Sensing, Environment and Transportation Engineering (RSETE), 2011 International Conference on, 24-26 June $20112011 . \quad$ pp 6463-6467. doi:10.1109/RSETE.2011.5965837

24. Makuuchi K, Cheng S (2012) Radiation processing of polymer materials and its industrial applications. John Wiley \& Sons,

25. Arora S, Ghosh T, Muth J (2007) Dielectric elastomer based prototype fiber actuators. Sensors and Actuators A: Physical 136 (1):321-328. doi:http://dx.doi.org/10.1016/j.sna.2006.10.044

26. Zhao X, Wang Q (2014) Harnessing large deformation and instabilities of soft dielectrics: Theory, experiment, and application. Applied Physics Reviews 1 (2):-. doi:doi:http://dx.doi.org/10.1063/1.4871696

27. Suo Z (2010) Theory of dielectric elastomers. Acta Mech Solida Sin 23 (6):549-578

28. Lu T, Huang J, Jordi C, Kovacs G, Huang R, Clarke DR, Suo Z (2012) Dielectric elastomer actuators under equal-biaxial forces, uniaxial forces, and uniaxial constraint of stiff fibers. Soft Matter 8 (22):6167-6173. doi:10.1039/C2SM25692D

29. Lei W, Wang R, Yang D, Hou G, Zhou X, Qiao H, Wang W, Tian M, Zhang L (2015) Design and preparation of bio-based dielectric elastomer with polar and plasticized side chains. RSC Advances 5 (59):47429-47438

30. Zhou Y, Jerrams S, Betts A, Chen L (2014) Fatigue life prediction of magnetorheological elastomers subjected to dynamic equi-biaxial cyclic loading. Materials Chemistry and Physics 146 (3):487-492. doi:http://dx.doi.org/10.1016/j.matchemphys.2014.03.059

31. Jerrams S, Murphy N, Hanley J (2012) The significance of equi-biaxial bubble inflation in determining elastomeric fatigue properties.

32. Landel RF, Nielsen LE (1993) Mechanical Properties of Polymers and Composites, Second Edition. Taylor \& Francis,

33. Kulkarni AJ, Zhou M, Ke FJ (2005) Orientation and size dependence of the elastic properties of zinc oxide nanobelts. Nanotechnology 16 (12):2749

34. Dimopoulos E, Trintis I, Munk-Nielsen S Comparison of the dielectric electroactive polymer generator energy harvesting cycles. In, 2013. pp 86870O-86870O-86813

35. Takala M (2010) Electrical insulation materials towards nanodielectrics. Tampereen teknillinen yliopisto Julkaisu-Tampere University of Technology Publication; 928

36. Sharma M, Madras G, Bose S (2014) Process induced electroactive [small beta]-polymorph in PVDF: effect on dielectric and ferroelectric properties. Physical Chemistry Chemical Physics 16 (28):14792-14799. doi:10.1039/C4CP01004C

37. Shim SE, Isayev AI (2001) Ultrasonic Devulcanization of Precipitated Silica-Filled Silicone Rubber. Rubber Chemistry and Technology 74 (2):303-316. doi:doi:10.5254/1.3544952

38. Luo B, Wang X, Wang Y, Li L (2014) Fabrication, characterization, properties and theoretical analysis of ceramic/PVDF composite flexible films with high dielectric constant and low dielectric loss. J Mater Chem A 2 (2):510-519. doi:10.1039/C3TA14107A

39. Gallone G, Carpi F, De Rossi D, Levita G, Marchetti A (2007) Dielectric constant enhancement in a silicone elastomer filled with lead magnesium niobate-lead titanate. Materials Science and Engineering: C 27 (1):110-116. doi:http://dx.doi.org/10.1016/j.msec.2006.03.003

40. Carpi F, Rossi DD (2005) Improvement of electromechanical actuating performances of a silicone dielectric elastomer by dispersion of titanium dioxide powder. Dielectrics and Electrical Insulation, IEEE Transactions on 12 (4):835-843. doi:10.1109/TDEI.2005.1511110 
41. Das SK, Choi SUS, Yu W, Pradeep T (2007) Theoretical Modeling of Thermal Conductivity in Nanofluids. In: Nanofluids. John Wiley \& Sons, Inc., pp 167-208. doi:10.1002/9780470180693.ch4 42. Namitha LK, Chameswary J, Ananthakumar S, Sebastian MT (2013) Effect of micro- and nano-fillers on the properties of silicone rubber-alumina flexible microwave substrate. Ceramics International 39 (6):7077-7087. doi:http://dx.doi.org/10.1016/j.ceramint.2013.02.047

43. Yang R, Wong CP, Qu J, Marinis T Effective dielectric constant prediction of polymer-ceramic composite based on self-consistent theory. In: Electronic Components \&amp; Technology Conference, 2000. 2000 Proceedings. 50th, 2000 2000. pp 615-618. doi:10.1109/ECTC.2000.853222 44. Okano T (1993) Molecular design of temperature-responsive polymers as intelligent materials. In: Dušek K (ed) Responsive Gels: Volume Transitions II, vol 110. Advances in Polymer Science. Springer Berlin Heidelberg, pp 179-197. doi:10.1007/BFb0021133

45. Poon YM, Shin FG (2004) A simple explicit formula for the effective dielectric constant of binary 0-3 composites. Journal of Materials Science 39 (4):1277-1281. doi:10.1023/B:JMSC.0000013886.21054.e4

46. Araújo MC, Costa CM, Lanceros-Méndez S (2014) Evaluation of dielectric models for ceramic/polymer composites: Effect of filler size and concentration. Journal of Non-Crystalline Solids 387 (0):6-15. doi:http://dx.doi.org/10.1016/j.jnoncrysol.2013.12.005

47. Dissado LA, Fothergill JC (1992) Electrical degradation and breakdown in polymers. vol 9. IET, 48. O'Dwyer J (1982) Breakdown in solid dielectrics. Electrical Insulation, IEEE Transactions on (6):484-487 